\section{Case Reports in Ophthalmology}

\title{
Use of Internal Limiting Membrane Autograft in Primary Vitrectomy for Rhegmatogenous Retinal Detachment
}

\author{
Sergio Eustolio Hernández-Da Mota Jorge Francisco Béjar-Cornejo \\ Clínica David, Unidad Oftalmológica, Universidad Michoacana (Michoacán State \\ University), Morelia, Mexico
}

\section{Keywords}

Autograft · Internal limiting membrane $\cdot$ Rhegmatogenous retinal detachment · Retinotomy

\begin{abstract}
During a pars plana vitrectomy, an unplanned retinotomy in the raphe was performed in a 55-year-old female patient with rhegmatogenous retinal detachment and proliferative vitreoretinopathy. Since diathermy and laser therapy were not available at that moment, it was decided to peel off a small graft of the internal limiting membrane adjacent to the retinotomy site which had been previously stained with Brilliant Blue $G$. The graft was displaced under perfluorocarbon fluids and placed inside the retinotomy. Three weeks after surgery, the apparent closure of the retinotomy was observed clinically.

\section{Introduction}

Internal limiting membrane (ILM) free autografts have been used to repair refractory macular holes instead of using conventional surgical techniques like vitrectomy and peeling off the ILM, with encouraging results according to several authors [1]. Furthermore, to treat retinal tears in retinal detachment surgery, laser therapy or cryotherapy are used with excellent results, achieving appropriate sealing of the tears and thus contributing to retinal reattachment [2]. Laser therapy is also applied for the transoperative treatment of retinoto- 


\section{Case Reports in Ophthalmology}

\begin{tabular}{l|l}
\hline DOI: $10.1159 / 000452941$ & (c) 2016 The Author(s). Published by S. Karger AG, Basel \\
\hline
\end{tabular} www.karger.com/cop

Hernández-Da Mota and Béjar-Cornejo: Use of Internal Limiting Membrane Autograft in Primary Vitrectomy for Rhegmatogenous Retinal Detachment

mies that are occasionally performed to drain the subretinal fluid. Not having those means to achieve tear sealing poses a complication that in some hospital sites, mainly in third world countries like Mexico, is not entirely uncommon.

In this case report we describe the use of an ILM autograft to seal a transoperative retinotomy in a patient who underwent primary vitrectomy for rhegmatogenous retinal detachment and proliferative vitreoretinopathy.

\section{Case Report}

A 55-year-old female patient came for consultation with sudden loss of vision and also reporting a rapidly progressive superior altitudinal scotoma of her right eye. On examination, the patient had a visual acuity of hand motion on her right eye, and fundus examination with a Goldman 3-mirror lens revealed total retinal detachment with peripheral horseshoe tears in the 1,2, 7, and 9 o'clock positions, with presence of an inferior and temporal fixed fold. Vitrectomy surgery was then performed with membrane peeling under perfluorocarbon fluids, placing a \#287 exoplant with a \#240 band and silicone oil as intraocular tamponade. The tears were all treated with laser therapy. While the air-fluid exchange was being completed, a retinotomy in the raphe was inadvertently made. Laser treatment of the retinotomy site was no longer possible at that moment due to malfunction of the laser device. Cryotherapy and diathermy devices were not available either.

$0.02 \mathrm{ml}$ of Brilliant Blue G (FLUORON GmbH, Ulm, Germany) were injected into the vitreous cavity to stain the ILM. Afterwards, a Tano scratcher and an ILM forceps were used to peel off a small graft of the ILM adjacent to the retinotomy site. Once obtained, it was displaced under a perfluorocarbon fluid bubble and placed inside the retinotomy (Fig. 1, Fig. 2). Finally, a perfluorocarbon fluid-air exchange was performed, and $5 \mathrm{ml}$ of silicone oil were injected into the vitreous cavity.

Three weeks later the retina was completely reattached and the retinotomy sealed with the ILM graft (Fig. 3). It was not possible to take an optical coherence tomography (OCT) image due to the presence of a lens opacity. The patient did not return for postoperative follow-up.

\section{Discussion}

Peeling of the ILM is nowadays considered one of the main steps that contribute to a higher success rate in macular hole surgery. This has been achieved more efficiently with the use of dyes such as Brilliant Blue $G$ that provide better visualization of such membrane [3, 4]. Furthermore, some techniques have been reported using an ILM flap as well as free ILM autografts over and inside the macular hole, with good anatomical and functional results according to several authors $[1,5,6]$.

Conventionally, to treat rhegmatogenous retinal tears, methods such as diathermy, cryotherapy or laser therapy have been used. In the latter, for example, an inflammation area is created due to the thermal effect of the laser. This effect induces the formation of a chorioretinal scar around the retinal tear that seals it and prevents vitreous fluid from entering into the subretinal space and detaching the retina again. In this case report we describe the use of an ILM autograft to block the retinotomy, since we did not have these conventional methods available anymore at that moment of the surgery. The apparent sealing of the tear 
at the 3-week postoperative follow-up could be observed clinically, although it was not possible to confirm this finding by an OCT image.

In different histological preparations, Müller cell remains were found in the ILM once it had been removed from the rest of the retina [7]. These cell remains might be involved in the migration and repositioning of photoreceptors as well as in the formation of fibroglial tissue. Hence, the ILM autograft might work as a potential source of Müller cell remains and as a scaffold where fibroglial tissue can probably grow, contributing to the sealing of the retinal defect $[1,5,8]$.

In their study of a modified technique of autologous transplantation of ILM for macular holes, Hernández-Da Mota and Béjar-Cornejo [9] reported the presence of OCT hyperreflective images where the ILM autograft was placed, which might suggest the presence of this type of tissue filling the macular hole defect. The same phenomenon might occur in rhegmatogenous retinal tears and retinotomies such as the one presented in this case report.

Animal studies as well as larger case series of patients and eventually comparative studies with conventional techniques are required to determine the real impact of the use of ILM autografts for the treatment of rhegmatogenous retinal detachment and retinal tears. Other possible applications of this surgical technique combined with a retinal pigment epithelium autograft might be in diseases such as albinism and degenerative myopia that have little pigmentation of the retinal pigment epithelium.

\section{Statement of Ethics}

The authors have no ethical conflicts to disclose.

\section{Disclosure Statement}

The authors report no conflicts of interest. This is an unfunded study.

\section{References}

$>1$ Morizane Y, Shiraga F, Kimura S, Hosokawa M, Shiode Y, Kawata T, Hosogi M, Shirakata Y, Okanouchi T: Autologous transplantation of the internal limiting membrane for refractory macular holes. Am J Ophthalmol 2014;157:861-869.e1.

2 Hee YH, Sheu SJ, Terasaki H: Primary vitrectomy in rhegmatogenous retinal detachment; in Ryan SJ (ed): Retina, ed 5. New York, Saunders Elsevier, 2013, vol 3, pp 1712-1720.

-3 Gaudric A, Tadayoni R: Macular hole; in Ryan SJ (ed): Retina, ed 5. New York, Saunders Elsevier, 2013, vol 3, pp 1962-1978.

4 Almony A, Nudleman E, Shah GK, Blinder KJ, Eliott DB, Mittra RA, Tewari A: Techniques, rationale, and outcomes of internal limiting membrane peeling. Retina 2012;32:877-891.

-5 Michalewska Z, Michalewski J, Adelman RA, Nawrocki J: Inverted internal limiting membrane flap technique for large macular holes. Ophthalmology 2010;117:2018-2025.

-6 Kuriyama S, Hayashi H, Jingami Y, Kuramoto N, Akita J, Matsumoto M: Efficacy of inverted internal limiting membrane flap technique for the treatment of macular hole in high myopia. Am J Ophthalmol 2013;156:125-131.e1.

-7 Beyazyildiz Ö, Tirhiş MH, Hekimoğlu ER, Beyazyildiz E, Kaymaz F, Yilmazbaş P, Öztürk F: Histopathological analysis of internal limiting membrane surgically peeled from eyes with epiretinal membrane. Curr Eye Res 2016;41:258-265.

-8 Oh J, Yang SM, Choi YM, Kim SW, Huh K: Glial proliferation after vitrectomy for a macular hole: a spectral domain optical coherence tomography study. Graefes Arch Clin Exp Ophthalmol 2013;251: 477-484. 
Case Reports in
Ophthalmology

Case Rep Ophthalmol 2016;7:251-255

DOI: $10.1159 / 000452941$

(C) 2016 The Author(s). Published by S. Karger AG, Basel www.karger.com/cop

Hernández-Da Mota and Béjar-Cornejo: Use of Internal Limiting Membrane Autograft in Primary Vitrectomy for Rhegmatogenous Retinal Detachment

-9 Hernández-da Mota SE, Béjar-Cornejo F: Modified technique of autologous transplantation of internal limiting membrane for macular hole (in Spanish). Cir Cir 2016, Epub ahead of print.

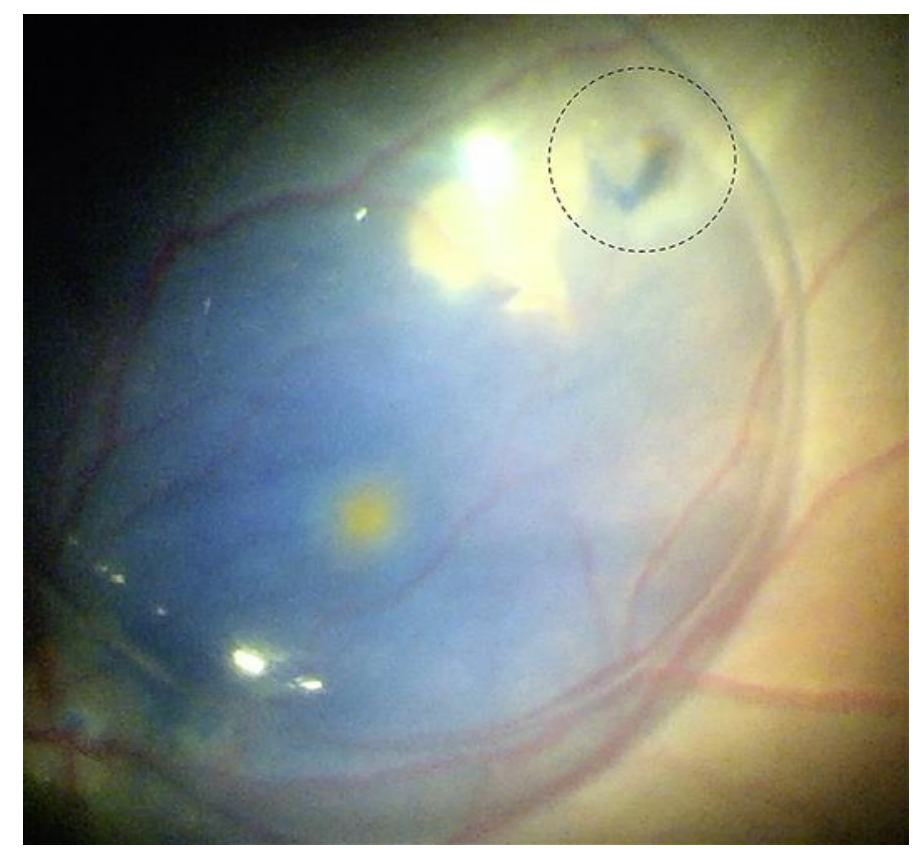

Fig. 1. Image of the internal limiting membrane autograft, dyed with Brilliant Blue G, being displaced under perfluorocarbon liquids to the retinotomy site (dotted circle). 


\section{Case Reports in Ophthalmology}

\begin{tabular}{l|l}
\hline Case Rep Ophthalmol 2016;7:251-255 \\
\hline DOI: 10.1159/000452941 & $\begin{array}{l}\text { @ } 2016 \text { The Author(s). Published by S. Karger AG, Basel } \\
\text { www.karger.com/cop }\end{array}$ \\
\hline
\end{tabular}

Hernández-Da Mota and Béjar-Cornejo: Use of Internal Limiting Membrane Autograft in Primary Vitrectomy for Rhegmatogenous Retinal Detachment

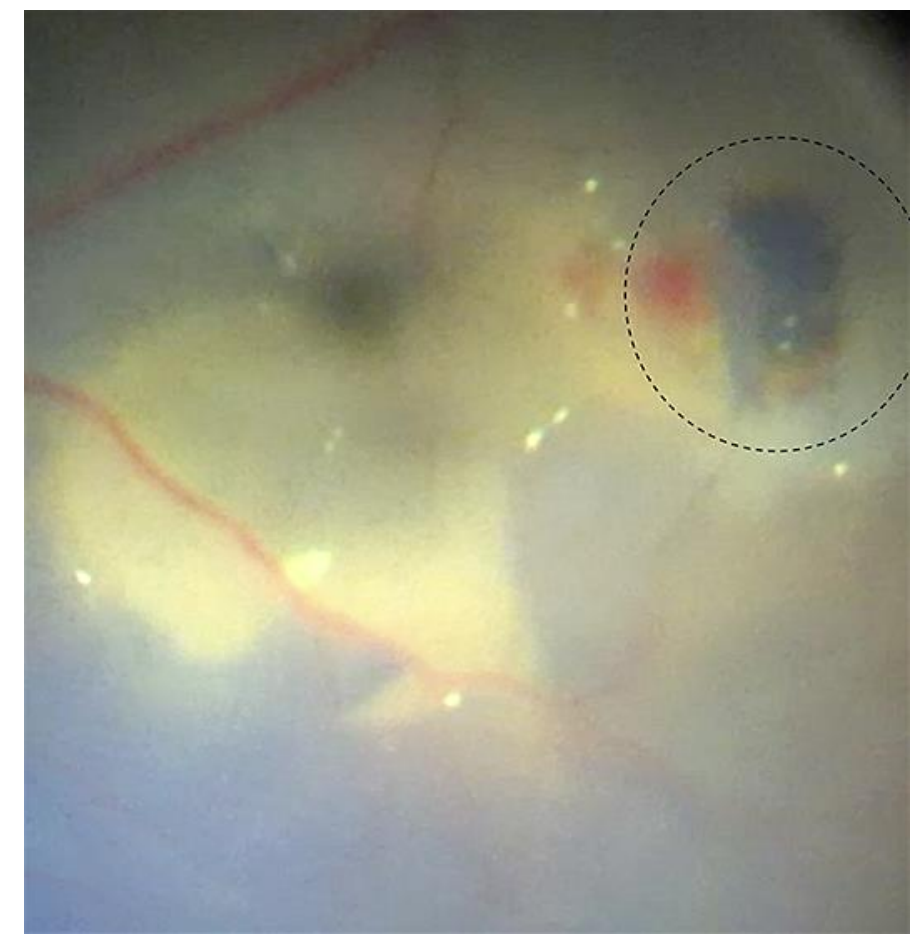

Fig. 2. Image of the internal limiting membrane autograft inside the retinotomy (dotted circle).

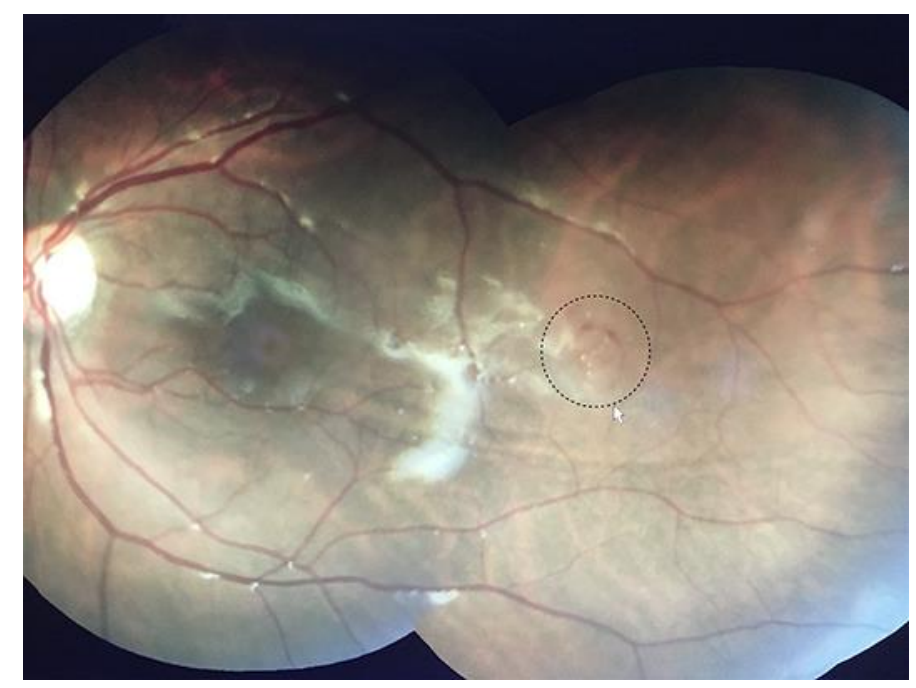

Fig. 3. Image of the apparently closed retinotomy area with the presence of the internal limiting membrane autograft 3 weeks after vitrectomy (arrow). 